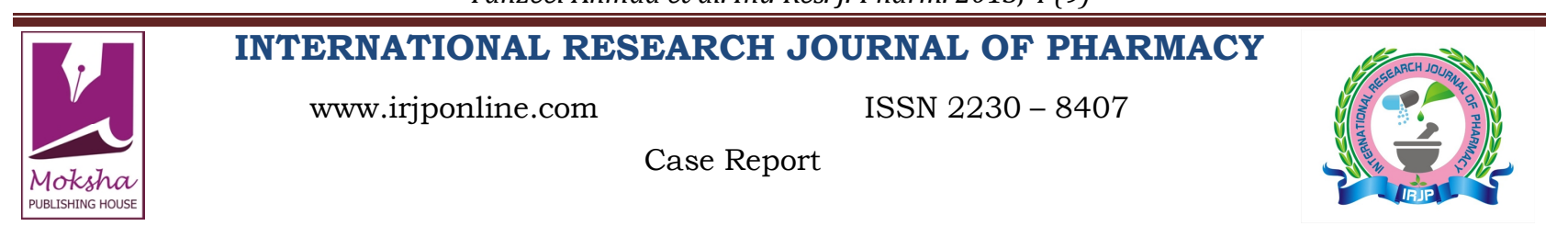

\title{
CLINICAL OUTCOME IN A PATIENT OF TAHAJURE MAFASIL OF KNEE JOINTS FOLLOWING APPLICATION OF LEECH THERAPY: A CASE REPORT
}

\author{
Tanzeel Ahmad, Javed A Khan* and HumyraTabasum \\ Department of Moalajat, National Institute of Unani Medicine, Bangalore, India \\ *Corresponding Author Email: jvd.khan@gmail.com
}

Article Received on: 19/08/13 Revised on: 01/09/13 Approved for publication: 10/09/13

DOI: $10.7897 / 2230-8407.04939$

IRJP is an official publication of Moksha Publishing House. Website: www.mokshaph.com

(C) All rights reserved.

\begin{abstract}
A male patient of 75 years attended the out patient department of National Institute of Unani Medicine Hospital with pain and stiffness in both knee joints. He was diagnosed as a case of Tahajuremafasil (Osteoarthritis). At the time of admission he was unable to do his daily routine work. However with leech therapy in 7 sittings with an interval of 6 days, the WOMAC score improved from 22.7 to 74 . It is suggested from this preliminary observation that leech therapy may be considered as the treatment modality in patients with osteoarthritis.

Keywords: Unani medicine, WOMAC, Tahajuremafasil, Osteoarthritis, Leech therapy
\end{abstract}

\section{INTRODUCTION}

In Unani literature, all joint diseases are described under a single terminology, Wajaulmafasil. Tahajuremafasil is that condition of Wajaul mafasil in which the joints become stiff and movement are severely restricted. It is caused by abnormal viscid material that squeezes into the joint space to get solidified or stiff akin to lime stone. It usually involves elderly persons and is associated with pain ${ }^{1,2}$. Tahajuremafasil can be clinically correlated with Osteoarthritis (OA). OA is a major cause of morbidity, physical limitation and increased health care utilization ${ }^{3}$. According to the World Health Organization, OA is the second most common musculoskeletal condition (30\%) after back pain $(50 \%)$. The reported prevalence of OA from a study in rural India is $5.78 \%{ }^{4}$. A recent WHO report on the worldwide burden of disease indicates that knee OA alone is likely to become the fourth most important cause of disability in women and the eighth most important in men. Knee OA is more common in Asians and Afro-Caribbeans. With the increase in population of the elderly people it has become the major health problem nowadays ${ }^{5}$. As it has no cure, the important goal of treatment is to relieve pain and stiffness and maintain and improve physical function ${ }^{6}$. In Unani system of medicine, leech therapy has been mentioned for the treatment of joint pain ${ }^{7}$. So in this case of Tahajuremafasil (osteoarthritis), leech therapy was used to improve the outcome of the ailment.

\section{Case report}

A 75 year old male patient, a known case of Diabetes, on regular treatment since 01 month, came to NIUM General OPD seeking advice for 15 years history of progressively worsening of pain in both knees. His knees were stiff for about 20 - 30 minutes when he arose in the morning and also for some minutes after getting up from sitting position. The condition got aggravated by squatting, kneeling and moving upstairs or downstairs and become worse during cold seasons and improve in the summer season. He also experienced stiffness upon prolonged immobility. There was no past history of trauma, fatigue weight loss, fever, breathlessness and stroke. The patient was of average built with mild antalgic gait. Physical examination of upper and lower limbs did not show any deformity. There was no evidence of clubbing, cyanosis or edema. Neurological examination did not reveal any abnormality. Distal pulses were intact and there was no sign of neurovascular compromise. Musculoskeletal examination revealed palpable crepitus upon passive range of motion of both knees. Patient was unable to flex or extend his knees completely. Patellofemoral crepitus was also found. Patient had pain free full range of movement of the lumbosacral joint. There were no signs of unequal leg lengths, muscle weakness, or muscle wasting. Initial routine examinations were normal except for blood glucose (FBS $116 \mathrm{mg} / \mathrm{dl}$, PPBS $143 \mathrm{mg} / \mathrm{dl})$. Bleeding Time was 2 minutes and Clotting Time was 4 minutes. X- Ray of both knee joints was done for final diagnosis. The patient was instructed to stop all previous medication that comprised of NSAID's and was prescribed Unani treatment with pharmacopoeal preparations of Qurs Ziabetus, Safoof Ziabetus, along with Leech application. 3 leeches were applied over each knee joint at the point of maximum tenderness in 7 sittings with an interval of 6 days. No adverse effect was experienced by the patient except for slight itching that got relieved within 10-12 hours of leech application without any further medication. Improvement was assessed according to WOMAC score that improved from 22.7 to 74 and VAS score that improved from intense at the time of admission to mild at the time of discharge. Flexion of the knee joints improved from 110 to 130 degrees. In the period of 45 days of hospital stay patient experienced $90 \%$ improvement in pain in left knee joint and $80 \%$ improvement in right knee joint. He also experienced improvement in stiffness by $80 \%$.

\section{DISCUSSION}

As a part of medication, bloodletting through leech therapy has been in use since antiquity and has an effective role in various ailments in Unani system of medicine including joint pain ${ }^{7}$. In classical Unani texts, the term Waj-ul-mafasil (arthritis) encompasses all joint diseases but the clinical manifestation of tahajure mafasil may be correlated to osteoarthritis mentioned in conventional medicine as it is associated with anatomical and physiological defects. In Unani literature, tahajur-e-mafasil is described as a disorder in which the matter present within the joints get solidified or 
stiff akin to lime stone (choona). It usually involves persons of hot temperament and is associated with mild pain or severe pain. For its management pharmacological, non pharmacological and dietary interventions have been mentioned. Non pharmacological modalities mentioned in classical Unani texts are dalk (massage), bloodletting through fas'd (venesection), taleeq (leech therapy) and hijamat bil shurt (Cupping with scarification). Ibne Sina and Majusi have mentioned that psychological factors, emotional states, over eating, alcohol intake play an important role in the causation of this disease along with the weakness of joint ${ }^{8-11}$. According to Ibn Sina the application of leech is more useful than cupping in letting off the blood from deeperparts of the body $^{12}$. During the course of 45 days of hospital stay significant improvement was observed in joint stiffness, pain, tenderness, swelling and restriction of movements. It may be due to the elimination of abnormal humours present locally around the joint as described by Razi, Ibn Sina, Majoosi and Rabban Tabri ${ }^{7,10,11,13}$. The effect may be due to the musakkinealam (analgesic) and muhallil (resolvent) effect of Leech therapy as Razi rightly described it in his book Alhavi Fil' $\mathrm{Tib}^{7}$. The musakkinealam (analgesic) and muhallil (resolvent) effect of Leech therapy may be explained in various ways. The saliva of leeches contain a variety of substances such as Hirudin, Hyluronidase, Histamine like vasodilators, collaginase, destalibase, inhibitors of kallikrein, superoxide production and poorly characterized anaesthetic compounds. These substances, might reach deeper tissue zones and possibly the joint spaces ${ }^{14}$. The hyaluronidase increases the membrane permeability, reduce the viscosity and promote the diffusion of injected fluids. Under the influence of this, other substances might reach the joint spaces and thus exert substantial effects in periarticular tissue and adjacent structure. It has been proved through Laser Doppler Flowmetry that there is a significant increase in the superficial skin perfusion following leech application especially $16 \mathrm{~mm}$ around the biting zone ${ }^{15}$. The anaesthetic present in the leech saliva affects the local nerve fibres and produce anaesthesia that can last several months and provide long term relief ${ }^{16}$. Physical effects of bloodletting may cause relief due to elimination /dilution of various substance which causes joint pain. Elimination also reduces the congestion which is responsible for pain. Taleeq (Leech therapy) could induce pain relief through antinociceptive effects and counter irritation. It may be possible that all mechanisms play a role in alleviating the symptoms of osteoarthritis. An important limitation is the open nature of this case study. That is, the placebo-like effects of leech therapy cannot be precisely assessed. Furthermore, this study may nothave lasted long enough to fully assess the long-term effect of leech therapy. However, in the trial on leech therapy for knee osteoarthritis, the beneficial effect decreased after 3 months ${ }^{17}$. Hence, for treating osteoarthritis of the knee joint on a long-term basis leech therapy may be repeated at regular intervals.

\section{CONCLUSION}

Leech therapy seems to be effective in relieving pain and improving joint function. The symptomatic improvement persisted until the end of the 2-months study period. A common minor side effect with leech therapy was local itching with erythema. Patients therefore should be informed about this frequent adverse effect. Although leech application may not prove safe in the patients with bleeding disorders, anaemia or those who are immunocompromised, it is believed safe for most other people. However, the results of this study are preliminary. The efficacy and safety of this treatment should be further tested in larger and long-term randomized trials.

\section{REFERENCES}

1. Khan MA. Akseere Aazam (Urdu translation by Mohd Kabeeruddin). New Delhi: Idara Kitabul Shifa; 2011. p. 836-45. PMCid:PMC3106434

2. Jurjani AH. Zakheera Khwarizam Shahi (Urdu translation by Hadi Hasan), Vol. $2^{\text {nd }}$ Part 6. New Delhi: Idara Kitabul Shifa; 2010. p. 640.

3. Lane NE, Schnitzer TJ. Cecil Medicine, $23^{\text {rd }}$ ed. Edinburgh: Saunders Elsevier; 2007. p. 283.

4. Das SK. API Text Book of Medicine. $8^{\text {th }}$ ed. Vol $1^{\text {st }}$. Mumbai: The Association of Physicians of India; 2008. p. 279.

5. Williams FMK, Spector DT. Medicine 2006; 34(9): 364-368. http://dx.doi.org/10.1053/j.mpmed.2006.06.011

6. Osteoarthritis. [homepage on the Internet]. American college of Rheumatology. Available from http://www.rheumatology.org; 2012.

7. Razi AB. Kitab Alhavi (Urdu translation by CCRUM). Vol. $11^{\text {th }}$. New Delhi: Ministry of H and FW, Govt. of India; 1997. p. 129.

8. Arzani A.Tibe Akbar (Urdu translation by Hkm. Hussain M). Deoband: Faisal publications; YNM: 618-28.

9. Chandpuri K. Moojizul Qanoon. New Delhi: Ministry of H and FW, Govt. of India; 1998. p. 403.

10. Ibne Sina, Al Quanoon Fil Tib (Urdu translation by Kantoori GH). Vol $3^{\text {rd }}$. Delhi: Idara Kitabul Shifa; 2007. p. 1119-25.

11. Majusi AI. Kamilus Sana (Urdu Translation by Kantoori GH). Vol $2^{\text {nd }}$. New Delhi: Idara Kitabush Shifa; 1889. p. 503-4.

12. Deuraseh N. Health And Medicine In the Islamic Tradition Based On The Book Of Medicine (Kitab Al-Tibb) Of Sahih Al-Bukhari. JISHIM 2006; 5: 2-14.

13. Tabri R. Firdous al hikmat. New Delhi: Faisal brothers; 2002. p. 291.

14. Michalsen A et al. Effectiveness of leech therapy in women with symptomatic arthrosis of the first carpometacarpal joint: A randomized controlled trial. International Association for the Study of Pain 2008; 137: 452-9.

15. Singh AK, Singh OP. Analgesic and anti- inflammatory activity of leech therapy in the management of arthritis. International Research Journal of Pharmacy 2012; 2(12): 172-4.

16. Grumbine NA, Nicholas A. Feature: reviving an ancient therapy to manage chronic pain. Podiatry Today 2003; 16: 46-53.

17. Andreas Michalsen, Stefanie Klotz, Rainer Lu Dtke, Susanne Moebus, Gu Nther Spahn and Gustav J Dobos. Effectiveness of Leech Therapy in Osteoarthritis of the Knee A Randomized, Controlled Trial. Ann Intern Med 2003; 139: 724-730. http://dx.doi.org/10.7326/0003-4819-139-9200311040-00006PMid:14597456

Cite this article as:

Tanzeel Ahmad, Javed A Khan and HumyraTabasum. Clinical outcome in a patient of Tahajure maffasil of knee joints following application of leech therapy: A case report. Int. Res. J. Pharm. 2013; 4(9):184-185 http://dx. doi.org/10.7897/2230-8407.04939 